\title{
A FORMULAÇÃO DE ESTRATÉGIAS PARA PEQUENAS EMPRESAS DE BASE TECNOLÓGICA
}

\author{
The strategy formulation \\ for small technology-based firms
}

\author{
Érica C. O. Pereira Berté 1 \\ Leonel Cezar Rodrigues ${ }^{2}$ \\ Martinho Isnard Almeida ${ }^{3}$
}

\section{Resumo}

Considera-se que uma empresa possui uma estratégia quando determinadamente faz seus produtos/serviços de forma diferente, mais inteligente e planejada do que seus rivais. Apesar de manterem em fundamento as mesmas características, formulá-las para uma grande ou microempresa são processos distintos. Parece ser mais singular ainda quando se analisa o caso das pequenas empresas de base tecnológica. Assim, o objeto deste trabalho é a análise da formulação de estratégias em pequenas empresas de base tecnológica, com o fim de propor contribuições ao processo de formulação de estratégias para esse tipo de empresa. Realizouse, para tanto, um estudo qualitativo, de multicasos, envolvendo seis pequenas empresas de

\footnotetext{
${ }^{1}$ Graduada em Administração pela Universidade Federal de Santa Catarina (UFSC) e em Ciências Contábeis pela Fundação Regional de Blumenau (FURB). Mestre em Administração pela UFSC e doutora pelo programa de pósgraduação da Faculdade de Economia, Administração e Contabilidade da Universidade de São Paulo. Atualmente reside nos Estados Unidos, é professora da Indiana University - Purdue University Columbus, no Departamento de Administração, Division of Business, 4601 Central Avenue, Columbus, IN, USA - 47203. E-mail: eberte@indiana. edu

${ }^{2}$ Graduado em Química pela Universidade Regional de Blumenau, especialização em Cooperação Técnica Internacional na FEA/USP. Tem mestrado e doutorado em Administração, pela Vanderbilt University, TN (USA). Atualmente é professor titular e pesquisador da Universidade Nove de Julho, Departamento de Administração, Av. Francisco Matarazzo, 612, São Paulo, SP, Brasil, 05001-100. E-mail: leonelcz@gmail.com ${ }^{3}$ Graduado em Administração de Empresas pela EAESP-FGV, com mestrado e doutorado pela FEA-USP, onde atualmente é professor livre-docente e consultor da Fundação Instituto de Administração (FIA-USP), Departamento de Administração, Universidade de São Paulo (USP), Av. Luciano Gualberto, 908, Cidade Universitária, São Paulo, SP, Brasil, 05508-900. E-mail: martinho@usp.br
} 
base tecnológica. A análise do processo de formulação de estratégias dessas empresas mostrou que o elemento fundamental nesse processo é a vocação técnica do empreendedor. É ela que determina a concepção do negócio, induzindo à formulação de estratégias de forma intuitiva e assistemática. As habilidades técnicas do microempresário parecem sobrepor-se às técnicas administrativas de análise ambiental, benchmarking e identificação de oportunidades, numa demonstração clara de atitude quase exclusiva de technology push. Considerando as características deste contexto, propõe-se um modelo de formulação de estratégias para essas empresas.

Palavras-chave: Estratégia; Empreendedorismo; Formulação de Processo e Pequena Empresa de Base Tecnológica.

\begin{abstract}
A company has a strategy when clearly offers its products or services in a distinctive form, more intelligent and planned versus the competition. Although there are similarities in formulating strategy for large or small companies, they are distinct processes. This seems to become even more singular when we analyze small technology based firms. The objective of this paper is to analyze the strategy formulation process for Small Technology Based Firms (STBF), aiming to contribute to the process of strategy formulation for this type of company. The methodology was designed as a qualitative research, based on a multiple case study approach, involving six STBF. The results of this work showed that the basic element in the process of strategy formulation is the technical vocation of the entrepreneur. It is the entrepreneur vocation that determines the conception of the business, inducing to the processes of strategy formulation in an intuitive and non-planned mode. The technical abilities of the entrepreneur seem to overcome the management techniques of environment analysis, benchmarking, and identification of opportunities, resulting in an attitude almost exclusive of technology push. Considering the characteristics of this context, a strategy formulation model applicable for this type of company is presented.
\end{abstract} Based Firms.

Keywords: Strategy, Entrepreneurship, Formulation Process and Small Technology-

\title{
1 Introdução
}

Pequenas empresas de base tecnológica contribuem para o desenvolvimento de uma nação por meio de importantes benefícios socioeconômicos, tais como, suporte ao processo de industrialização, desenvolvimento tecnológico e abertura de novos empregos. Essas empresas constituem, portanto, importante foco de atenção por parte do governo e da sociedade, em qualquer nação. Quase todos os países suportam programas específicos de estímulo e políticas de apoio financeiro, técnico e administrativo às pequenas empresas de base tecnológica, como uma garantia da capacidade competitiva da nação.

Apesar de todos esses esforços, as pequenas empresas de base tecnológica enfrentam tempos difíceis para sobreviver e consolidar seus negócios no mercado. Muitos autores da literatura especializada, como Pinho et al. (2002), atribuem os problemas de sobrevivência das pequenas empresas de base tecnológica à falta de capital, de recursos humanos especializados e à natureza técnica de seus produtos. Acredita-se também que a falta de habilidade administrativa de seus executivos soma-se às dificuldades de sobrevivência. Esses fatos e a pressão das necessidades de faturamento para pagar as despesas operacionais, especialmente em seus primeiros anos de operação, deixam quase nenhuma folga para os executivos formularem ou construírem estratégias competitivas mais efetivas. 
Bhide (1996) e Berry (1998) urgem em que as empresas de bases tecnológicas tornemse mais pró-ativas, como mecanismo de sobrevivência no longo prazo, em vez de permanecerem reativas às mudanças do mercado e de seu ambiente de operação. Os autores ainda estimulamnas a formularem estratégias que possam garantir futuras operações, tanto no modus operandi em escala como no de inovação. Em qualquer caso, à medida que as empresas crescem, tornam-se mais complexas e sofisticadas, necessitando de uma estratégia corporativa mais clara e eficaz. Khogh e Cusumano (2001) e Hill e Jones (2004) afirmam que as empresas que quiserem crescer e alcançar desempenho superior precisam desenvolver um plano de crescimento baseado em combinações inteligentes de produto/mercado, de tamanho da participação no mercado, de know-how e das estruturas organizacionais que deverão suportar a estratégia.

As políticas de investimentos e estratégias de pesquisa e desenvolvimento em pequenas empresas de base tecnológica devem estar sincronizadas com o que Rodrigues, Riscarolli e Almeida (2004) chamam de "maturidade tecnológica". A maturidade tecnológica dá especialidade ao processo de formulação de estratégias nas pequenas empresas de base tecnológica e cria momentum para o seu processo de crescimento e consolidação. A experiência na gestão de pequenas empresas de base tecnológica, como demonstrado por Almeida (2003), indica que o processo de formulação de estratégias segue e é especialmente influenciado por outros fatores organizacionais.

\subsection{Contexto e objetivo}

Genericamente, a formulação de estratégia, como um processo, está ligada ao planejamento estratégico da empresa, e a este precedem a análise ambiental e estrutural. Existe uma grande variedade de modelos de formulação de estratégia (MINTZBERG e QUINN, 2001; PORTER, 1990; TREGOE e ZIMMERMANN, 1988; SLYWOTZKY e MORRISON, 1998; MILES e SNOW, 1978; WHITTINGTON, 2002). Todos são modelos validados em diferentes estudos e aceitos pela academia. No entanto, decidiu-se adotar o Modelo de Planejamento Estratégico de Almeida (2003), porque esse modelo foi concebido, baseado e proposto para elaborar o plano estratégico e formular estratégias para pequenas empresas. O modelo também tem sido testado há 15 anos em muitas pesquisas de dissertação e de teses de doutorado na academia brasileira, provando consistência e viabilidade.

Considerando as nuanças das pequenas empresas de base tecnológica e também acreditando que uma estratégia de negócio efetiva pode ser decisiva para a consolidação e crescimento da empresa, este artigo concentra-se no processo de formulação de estratégias para pequenas empresas de base tecnológica. O objetivo é propor contribuições ao seu processo de formulação de estratégias. Para fazê-lo, estudou-se o processo de formulação de estratégias de seis pequenas empresas de base tecnológica no Brasil, com orientação mercadológica global, usando o Modelo de Planejamento Estratégico de Almeida (2003) como guia.

\section{Revisando a literatura especializada: a pequena empresa de base tecnológica}

O conceito de pequena empresa de base tecnológica origina-se da combinação do conceito de pequenas empresas e empresa de base tecnológica. Beaver e Prince (2004) afirmam que a definição e classificação de pequenas empresas é complexa. A classificação varia de nação para nação, mas seus fundamentos seguem um raciocínio qualitativo (por exemplo, 
estruturas simples e processos administrativos holísticos) e quantitativo básicos (por exemplo, o número de empregados e faturamento anual) ou a combinação de ambos.

No Brasil a classificação de pequenas empresas obedece aos critérios de classificação determinados pelo Serviço Brasileiro de Apoio às Micro e Pequenas Empresas (SEBRAE) e pelo Banco Nacional de Desenvolvimento Econômico e Social (BNDES). Segundo o Sebrae (2007), uma empresa é considerada pequena quando emprega entre 20 e 49 empregados. Em termos de faturamento anual, uma pequena empresa fatura entre US\$200.000 e 1.000 .000 por ano. O BNDES estabelece que uma empresa deve ser considerada pequena quando seu faturamento fica entre US\$ 500.000 e US\$ 5.000 .000 por ano. Neste trabalho, considera-se a classificação do BNDES para a classificação das empresas selecionadas nesta pesquisa.

\subsection{Características das pequenas empresas de base tecnológica}

Segundo a Associação Catarinense de Alta Tecnologia (ACATE, 2007), um negócio de base tecnológica é baseado (a) num processo ou produto resultado de pesquisa científica e para o qual o valor integrado vem de áreas de alta tecnologia, tais como: computadores, biotecnologia, química fina, novos materiais, mecânica de precisão e outras; e (b) de uma aplicação de conhecimento científico, originada no domínio de técnicas complexas e trabalhos de alta qualificação técnica. Ainda, de acordo com a Associação Nacional para a Promoção de Empresas e Entidades de Alta Tecnologia (ANPROTEC), no Brasil, uma empresa de base tecnológica é um "empreendimento cuja atividade principal concentra-se no desenvolvimento de novos produtos e processos, baseados numa aplicação sistemática do conhecimento científico e tecnológico e na utilização de técnicas pioneiras e avançadas" (ANPROTEC, 2002, p. 47). Apesar de não explicitada, a inovação tecnológica é um dos fundamentos dessas empresas e está incorporada na própria definição destas, sendo uma questão central no ponto de vista de Ferro e Torko-Mian (1988).

Inovação, nessas empresas, é geralmente um novo produto, mas não necessariamente um produto inédito (SANTOS, 1987). Para garantir a inovação em empresas de base tecnológica, é necessário contar com recursos humanos de elevado nível educacional e investir pesadamente em engenharia, pesquisa e desenvolvimento.

O risco inerente da inovação para o negócio é uma diferença básica entre empresas de base tecnológica e empresas de manufatura não fundamentadas em domínio tecnológico. Produtos de alta tecnologia geram incertezas aos negócios porque dependem da velocidade de disseminação da inovação, dos padrões tecnológicos a serem adotados e do tipo de mudanças a ocorrer no mercado e na sociedade (CARVALHO et al., 2000). Pequenas empresas de base tecnológica também correm riscos maiores por causa da rápida obsolescência, de efeitos indesejáveis da tecnologia e de disrupções tecnológicas originadas em investimentos de pesquisa e desenvolvimento.

Outra característica das pequenas empresas de base tecnológica é sua estratégia de entrada no mercado. Em geral, usam o princípio da technology push, em vez de uma estratégia de demand pull (LEITE, 2002). Na primeira, as empresas empurram seus produtos ao mercado sem se preocupar se o mercado quer os produtos com as funções e design oferecidos. Na segunda, combinam suas capacidades tecnológicas, função e design dos produtos, com as oportunidades e demandas existentes do mercado. Na medida em que lhes falta experiência, as pequenas empresas de base tecnológica tornam-se altamente vulneráveis a manobras de concorrentes, até aprenderem a lidar com o mercado, identificar seus padrões de aceitação e demandas latentes. 


\subsection{Estratégia de inovação}

A estratégia de inovação numa empresa de base tecnológica é mais bem representada pelo Modelo de Maturidade Tecnológica de Rodrigues, Riscarolli e Almeida (2004). O modelo, apresentado na Figura 1, aplica-se a qualquer tipo e tamanho de empresa de base tecnológica e traz a relação entre a maturidade tecnológica e a evolução estrutural da organização. O modelo mostra que empresas de bases tecnológicas podem operar em três opções estratégicas. Na primeira opção, a empresa compete por meio da inovação na tecnologia de produto - fase I do modelo. A empresa persegue distinção e diferenciação pela introdução de novos produtos a preços prêmios. Essa fase tipifica o comportamento organizacional, cultura e valores mais comuns de uma empresa de base tecnológica.

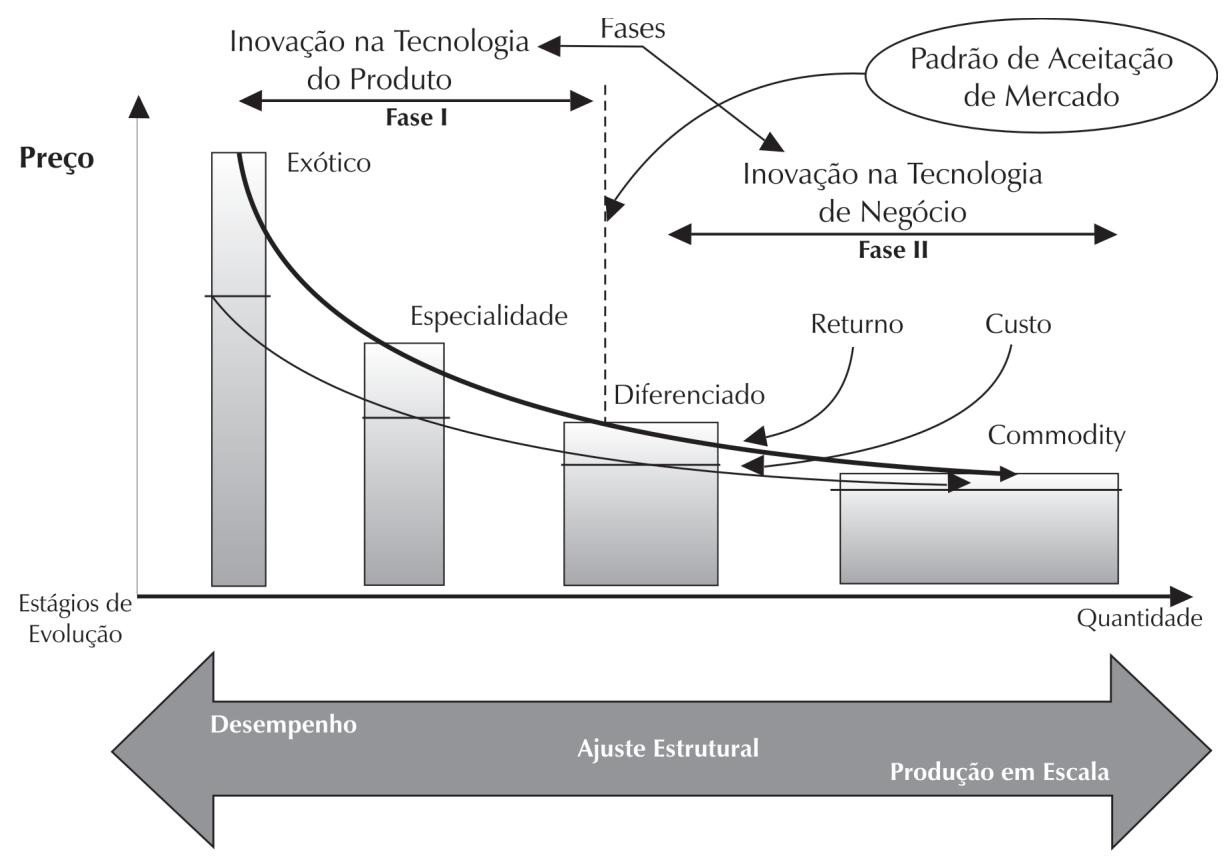

Fonte: Rodrigues, Riscarolli e Almeida (2004, p. 11).

Figura 1 - Modelo de maturidade tecnológica.

Na segunda opção estratégica, a empresa busca os padrões de aceitação mercadológica para seus produtos e compete por meio da produção em escala. Nessa fase, a empresa concentra sua estratégia de inovação na tecnologia do negócio (fase II). Ajustes estruturais, porém, são necessários para competir em escala (padronização de processos e procedimentos). Dessa forma, as empresas evoluem para um melhor equilíbrio entre (a) flexibilidade estrutural necessária na primeira fase, e (b) os processos e procedimentos padrões nesta fase. Na primeira fase, a inovação foca os produtos, analisando atributos tangíveis, tais como: desempenho, compatibilidade, facilidade de uso entre outros. Na fase II, a inovação foca a essência do negócio buscando fontes alternativas de pagamento e aperfeiçoamento dos atributos de acesso, tais como: preço, financiamento, disponibilidade dos produtos e semelhantes.

Na terceira opção estratégica, as empresas competem na produção em escala (fase II), porém, inovando na ponta. Nessa opção, os produtos fabricados em série são personalizados por seu redesenho, por exemplo. Eles se tornam novos produtos e são vendidos a preços prêmios, empurrando o negócio novamente para a fase I (inovação na tecnologia de produto). Obviamente empresas de base tecnológica, em geral, operam na opção I. 


\subsection{O processo de formulação de estratégias}

Mintzberg e Quinn (2001, p. 19) afirmam que "não há uma definição universalmente aceita" para a estratégia. A literatura especializada lida com uma gama muito ampla de abordagens para definir estratégia, que devem ser entendidas como complementares umas das outras. No conceito de planejamento racional e do modelo de aprendizagem intuitiva (MCCARTHY; LEAVY, 2000) pode-se encontrar uma base racional para a formulação de estratégias. O modelo de planejamento racional envolve o conceito tradicional de estratégia, como uma decisão voluntária da alta administração das empresas para determinar, formalmente, sua direção e posicionamento.

O modelo de aprendizagem intuitiva é mais bem entendido a partir dos 5 " $\mathrm{p}^{\prime} \mathrm{s}$ " da estratégia de Mintzberg e Quinn (2001): (a) Plano - a estratégia segue um curso deliberado de ações, determinado pela organização; (b) Padrão -a estratégia segue um curso de ações resultante de um comportamento organizacional consistente; (c) Pretenso - a estratégia segue ações objetivando enganar os competidores; (d) Posição - a estratégia suporta uma posição competitiva específica no mercado; e (e) Perspectiva - a estratégia segue a forma e o modo como são vistos o negócio, o mercado e os competidores, pela administração.

A definição de estratégia como padrão sugere que a estratégia seja um curso de ações não previamente determinadas (estratégias formuladas), mas também um curso de ações originadas ao longo do tempo (estratégias construídas). Mintzberg e Quinn (2001) afirmam que quando a estratégia se origina do Plano ou de uma decisão voluntária, torna-se uma estratégia deliberada. Quando a estratégia origina-se de um Padrão em vigência na empresa, torna-se uma estratégia emergente. Uma estratégia deliberada requer certo grau de controle, enquanto a estratégia emergente requer um processo de aprendizagem mais longo na empresa. A Figura 2 mostra como essas estratégias são formadas na organização.

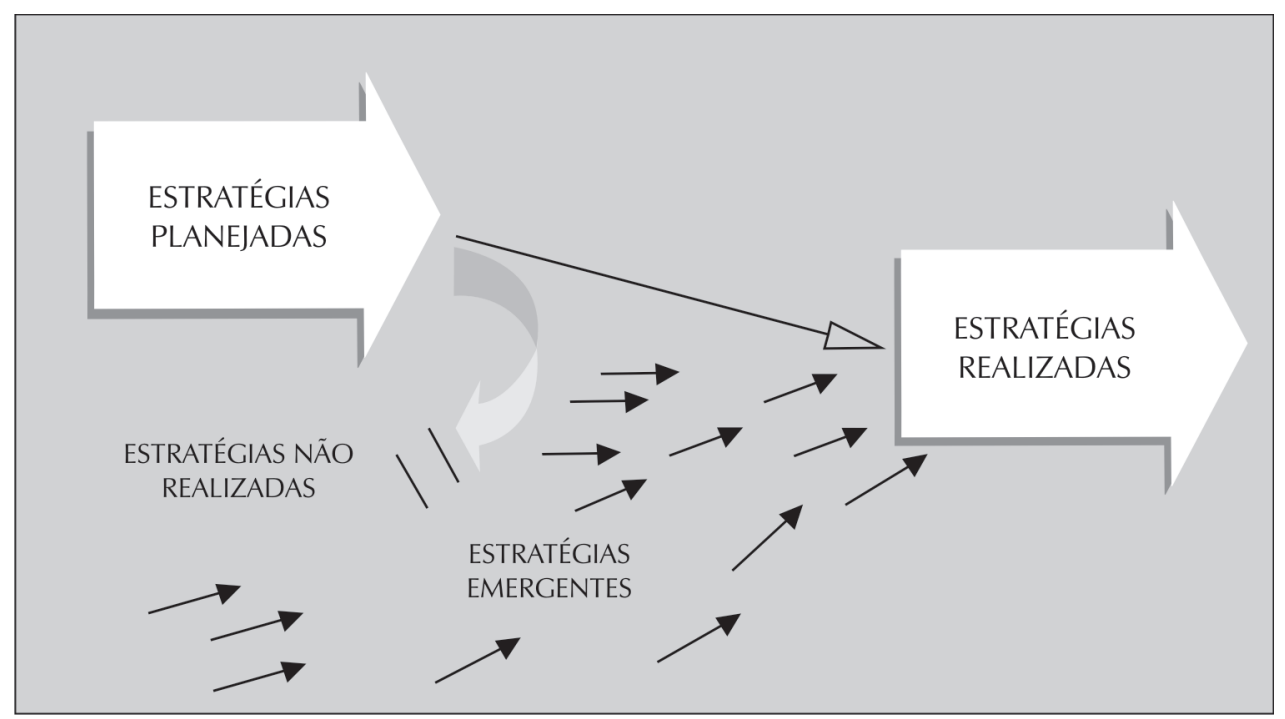

Fonte: Mintzberg e Quinn (2001, p. 29).

Figura 2 - Estratégias deliberadas e emergentes.

Mintzberg, Ahlstrand e Lampel (2000) sugerem que não há uma estratégia perfeitamente deliberada ou emergente. Estrategistas eficientes "misturam-nas de forma a que possam refletir as condições organizacionais correntes, especialmente a habilidade de antecipar-se a eventos indesejáveis ou reagir a eventos não esperados" (MINTZBERG, AHLSTRAND e LAMPEL, 2000, p.18). Um requisito importante é que a empresa deve prover as condições para o florescimento 
das estratégias deliberadas e emergentes e a organização, com controle planejado, possa estimular o aprendizado.

\subsection{O processo de formulação de estratégias de Whittington}

É útil e importante também discutir a visão de Whittington (2002) sobre a formulação de estratégia. Esse autor sintetiza as diversas abordagens sobre a formulação de estratégia, discutidas acima. Para Whittington (2002), a estratégia pode ser formulada de acordo com dois critérios: resultados e processos. A formulação por critérios de resultados lida com os objetivos da estratégia. Objetivos podem variar de aspectos econômicos - maximização dos lucros - até a pluralidade dos interesses organizacionais, legitimidade social e aceitação dos acionistas. A formulação de estratégia por processos fundamenta-se na forma, deliberada ou emergente, de construção da estratégia. De acordo com esses critérios, a estratégia pode ser construída em quatro diferentes caminhos: clássico, revolucionário, processual e sistêmico. Ambos os processos foram discutidos acima e a visão de Whittington (2002) de formulação de estratégias é mostrada na Figura 3.

As abordagens - clássica e evolucionária - para formular estratégia voltam-se para a maximização dos lucros e seguem o modelo de planejamento racional discutido anteriormente. A estratégia, nesse caso, resulta de um planejamento de longo prazo. A formulação clássica de estratégias subentende que a estratégia seja deliberada, isto é, determinada pela alta administração da empresa, visando ao lucro ou lucratividade da empresa. A abordagem clássica é indicada para ambientes operacionais estáveis.

A abordagem evolucionária é normalmente decorrente de uma adaptação organizacional ao ambiente. As empresas não podem adaptar-se de forma deliberada, porque podem ter habilidades limitadas para predizer e reagir em tempo às turbulências ambientais. Por isso, a adaptação é emergente, isto é, surge no contexto interno da empresa e constrói a estratégia gradativamente de baixo para cima. Em geral, essas estratégias são construídas por causa de contextos turbulentos em que a empresa deve operar. Nesses casos, é necessário inovar para garantir uma melhor aceitação pelo mercado. Assim, a abordagem evolucionária é recomendada para ambientes não previsíveis, que requeiram graus de inovação maiores e maior capacidade de competir.

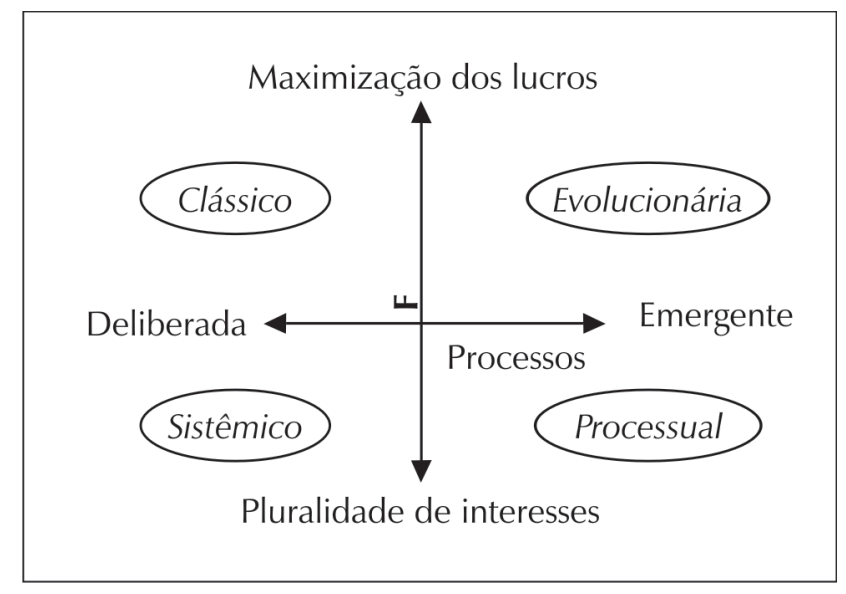

Fonte: Adaptado de Whittington (2002).

Figura 3 - Perspectivas gerais sobre a estratégia. 
A abordagem processual, da mesma forma que a evolucionária, constrói a estratégia como um processo emergente. A diferença é que o objetivo da abordagem processual tenta fazer com que a estratégia responda a interesses pluralistas dentro da organização, não necessariamente à maximização do lucro. De fato, a abordagem processual visa a ajustar ou direcionar os processos organizacionais e de negócios para que as coalizões de indivíduos, que barganham entre si para achar soluções, sejam coerentes em relação aos objetivos da empresa.

Finalmente, a abordagem sistêmica de formulação de estratégia é construída considerando o ponto de vista sociológico do negócio. É, porém, uma estratégia deliberada. A formulação da estratégia está relacionada às características sociais dos estrategistas e do contexto social em que se inserem as empresas. A estratégia fica muito influenciada pelas normas culturais da comunidade local. Dessa forma, o contexto organizacional é o responsável pela escolha da melhor estratégia.

\subsection{Escolas de formulação de estratégias}

Mintzberg, Ahlstrand e Lampel (2000) também trouxeram importantes contribuições para o conceito de formulação de estratégias, como resultado de um estudo em dois mil artigos sobre formulação de estratégias. Isso permitiu aos autores classificar os trabalhos acadêmicos sobre estratégia em dez escolas de formulação de estratégias, divididas em dois grandes grupos: um de escolas prescritivas e outro de descritivas. As escolas prescritivas envolvem um subgrupo de três escolas, no qual a formulação de estratégias é uma tentativa consciente de alinhar a organização às suas condições ambientais. Essas escolas abordam a formulação de estratégias como processos: conceptivos (escola do desenho), formais (escola do planejamento) e analíticos (escola do posicionamento).

O outro grande grupo de escolas (descritivas) envolve as outras sete escolas: (1) escola do empreendedorismo, na qual a formulação da estratégia é um processo visionário; (2) a escola cognitiva, que sustenta que a formulação da estratégia é um processo de esquema mental; (3) a escola do aprendizado, na qual a formulação da estratégia é um resultado de um processo emergente de atitudes e objetivos; (4) a escola política, que considera a estratégia com um resultado de diretrizes originadas nos processos de conflitos e lutas pelo poder interno; (5) a escola cultural, que defende a formulação da estratégia como um processo determinado por padrões ideológicos; (6) a escola ambientalista, que sustenta que a formulação da estratégia vem de um processo passivo, determinado pelas forças ambientais incontroláveis; e (7) a escola da configuração, na qual a formulação da estratégia é um processo totalmente integrado na estrutura da organização.

A escola prescritiva envolve os fundamentos de muitos modelos recentes de planejamento estratégico que incorporam a formulação de estratégias. Entre esses modelos aponta-se o Modelo de Planejamento Estratégico de Almeida (2003), que não é uma adaptação de modelos existentes desenvolvidos para grandes empresas, pois foi, anteriormente, desenvolvido para pequenas empresas e tornou-se comprovadamente útil também para grandes empresas.

\subsection{O modelo Almeida de planejamento estratégico}

Como já assinalado, o modelo de Planejamento Estratégico de Almeida (2003) para pequenas empresas orienta-se para a formulação de estratégias em pequenas empresas. $\mathrm{O}$ autor apresenta a formulação de estratégias nas primeiras três fases do modelo (orientação, 
diagnose e direção), conforme Figura 4. Uma vez que o processo de planejamento estratégico, como um todo, não é o foco deste trabalho, concentrar-se-á, aqui, apenas nestas três fases.

$\mathrm{Na}$ fase de Orientação, as Diretrizes Superiores são elementos mais presentes em grandes corporações. Por exemplo, numa unidade estratégica de negócio, pode-se considerar diretrizes superiores vindo da matriz da corporação. Da mesma forma, Missão numa pequena empresa, apesar de ser o elemento circunscritor dos "limites da operação e [...] de indicar as possibilidades de expansão" da empresa (ALMEIDA, 2003, p. 15), é normalmente definida para empresas maiores e mais consolidadas. Para pequenas empresas, o autor coloca a Vocação do empreendedor, como o principal volante do posicionamento do negócio e da alocação dos recursos na empresa. A formulação da Visão é igualmente uma ação da fase de Orientação, porque vem invariavelmente influenciada pelo tipo de educação e experiência do empreendedor.

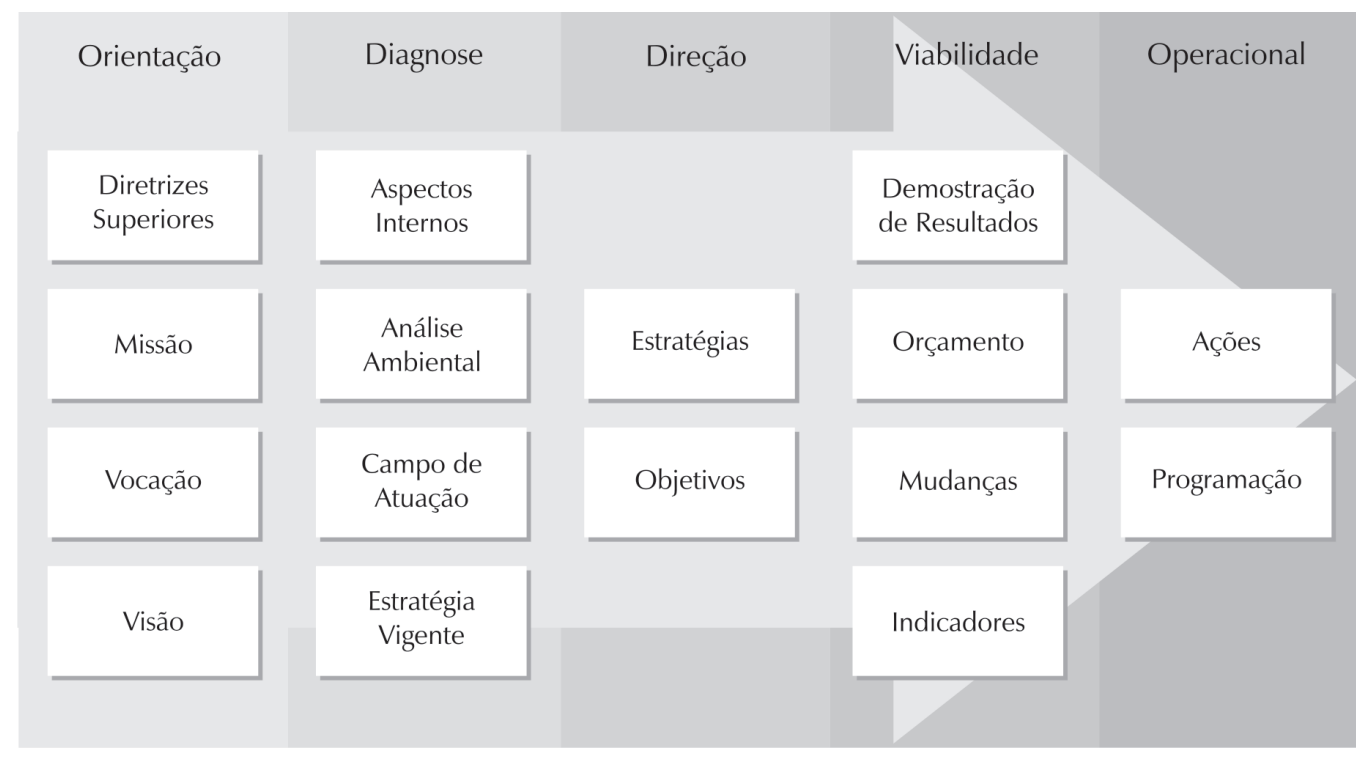

Fonte: Almeida (2003, p. 42).

Figura 4 - Processo de planejamento estratégico de Almeida.

A fase da Diagnose do modelo também merece mais detalhes. Os Aspectos Internos referem-se à identificação de forças e fraquezas da empresa. A Análise Ambiental envolve a análise de oportunidades e ameaças para o negócio, existentes no ambiente de operação da empresa. O estágio de Campo de Atuação refere-se à identificação do setor econômico em que a empresa opera. Essa análise é uma confirmação entre a missão e a vocação, isto é, entre o que os membros da empresa pensam que estão operando e sua realidade operacional. Finalmente, na Estratégia Vigente, os estrategistas identificam as estratégias em uso e avaliam sua validade aos novos propósitos da empresa.

A fase da Direção concerne ao desenvolvimento das novas estratégias e a definição dos novos objetivos estratégicos. Dando apropriada atenção às informações ambientais e aos dados institucionais, os estrategistas podem estabelecer estratégias que suportem os novos objetivos da empresa, de forma mais consistente e eficaz.

\section{Método da pesquisa}

A pesquisa foi desenhada como um estudo de multicasos, obedecendo à estrutura de análise de casos proposta por Yin (2005). Foram escolhidas seis empresas, seguindo orientações 
de Eisenhardt (1989), que exorta a consubstanciar implicações teóricas de um conjunto não inferior a quatro e não superior a dez casos.

A seleção das empresas obedeceu a três critérios básicos: (a) responder aos requisitos de empresa de base tecnológica, de acordo com o conceito da Anprotec (2002); (b) estar classificada como pequena empresa, segundo o BNDES (2002); e (c) estar em atividade há dez anos no mínimo e apresentar crescimento no faturamento bruto anual positivo nos últimos cinco anos. Os dados foram coletados por meio de roteiro de entrevista semi-estruturado, baseado no Modelo de Almeida (2003), aplicado ao sócio principal de cada empresa, como os sujeitos sociais da pesquisa.

\section{Análise dos resultados}

As empresas pesquisadas operam nos setores eletrônico e de software, setores tradicionais de alta tecnologia. Todas possuem experiência em incubadoras e cinco delas estão alocadas em Parques de Alta Tecnologia ou em Condomínio Industrial de Alta Tecnologia. Exceto uma, todas as empresas pesquisadas possuem certificação ISO 9001:2000 e 14001.

Todas as empresas foram estabelecidas no início da década de 1990; quatro delas possuem natureza constitutiva legal de limitada e duas são sociedade anônima. No conjunto das empresas, o número de proprietários varia entre 1 e 18. Apesar de serem empresas de base tecnológica, somente duas delas possuem patentes (uma em nível nacional e outra em nível internacional) de produtos ou processos. A razão alegada para não terem feito depósito de patentes relaciona-se à percepção de maior segurança das empresas ou seus proprietários, pela não abertura dos fundamentos tecnológicos de seus produtos e processos.

\subsection{Análise de conteúdo}

Obedecendo às fases do modelo de planejamento estratégico de Almeida (2003), as empresas foram estudas quanto às suas formas de realizar os estágios das fases de Orientação, Diagnose e Direção. Cada fase será comentada a seguir.

\subsubsection{Fase de orientação}

Diretrizes Superiores. As Diretrizes Superiores não foram consideradas na pesquisa, porque as empresas não estão afiliadas a matrizes e, portanto, não há diretrizes superiores a serem obedecidas. Pode-se observar uma grande facilidade de comunicação entre os empreendedores e seus funcionários. Nessas empresas, políticas e grandes diretrizes corporativas provêm dos empreendedores e executivos. Tais políticas e diretrizes são facilmente incorporadas e obedecidas pela empresa toda, que tem uma estrutura hierárquica simples, facilitando esse processo.

Missão. Como todas as empresas foram incubadas, todas tinham um Plano de Negócio, no qual constava sua missão. Em geral, porém, a missão expressa no plano de negócio foi proposta para fins burocráticos do plano. Uma das empresas reformulou sua missão e também a visão, mais recentemente, para obtenção da certificação ISO 9001:2000. Para outras três, as formulações são também mais recentes, oriundas no processo de planejamento estratégico pelo qual passaram. Contêm, portanto, uma expressão mais madura de suas capacidades e orientação mercadológica. 


\begin{tabular}{|c|c|c|}
\hline Empresas & Vocação da empresa & $\begin{array}{l}\text { Área da formação técnica } \\
\text { dos empreendedores }\end{array}$ \\
\hline Reason & Soluções de alta tecnologia para o setor elétrico. & Engenharia Elétrica \\
\hline Cebra & Fontes de energia e conversores estáticos & Engenharia Eletrônica \\
\hline Reivax & $\begin{array}{l}\text { Equipamentos de controle para sistemas de } \\
\text { geração de energia elétrica. }\end{array}$ & Engenharia Elétrica \\
\hline Cianet & $\begin{array}{l}\text { Equipamentos para comunicação digital de } \\
\text { dados. }\end{array}$ & $\begin{array}{l}\text { Engenharia Elétrica } \\
\text { Engenharia de Automação e Controle } \\
\text { Administração }\end{array}$ \\
\hline Directa & $\begin{array}{l}\text { Sistemas de Administração de processos de } \\
\text { automação de Manufatura. }\end{array}$ & $\begin{array}{l}\text { Análise de Sistemas } \\
\text { Engenharia Elétrica } \\
\text { Administração } \\
\text { Engenharia Mecânica }\end{array}$ \\
\hline Brasystem & $\begin{array}{l}\text { Sistema de automação de lojas, bares e } \\
\text { restaurantes (comercial). }\end{array}$ & Análise de Sistemas \\
\hline
\end{tabular}

Fonte: Dados da pesquisa

Quadro 1 - Relação entre a formação técnica do empreendedor e a vocação da empresa.

Visão. Assim como no caso da formulação da missão, todas, exceto uma empresa, têm formalizado sua visão de negócio. A formulação da visão também evoluiu, segundo os entrevistados, de um formato visionário (feito pelo empreendedor) para uma proposição de visão mais balanceada e viável, algumas com explicitação da participação mercadológica, outras com explicitação das competências centrais e lucratividade. Isso sugere uma forte interferência da vocação profissional do empreendedor (dono) ou do principal executivo no direcionamento da empresa nos primeiros anos do negócio.

Vocação. Uma empresa de base tecnológica, em geral, está mais propensa a ser influenciada pelo conhecimento profissional de seu fundador. No caso das empresas pesquisadas, percebeu-se uma correlação direta entre o campo de atuação da empresa e a especialidade profissional de seu fundador. Tais correlações são mostradas no Quadro 1.

\subsubsection{Fase de diagnose}

Análise dos aspectos internos. A análise dos aspectos internos refere-se à avaliação dos fatores internos (identificação dos pontos fortes e seleção dos fatores chaves de sucesso) que são decisivos para o sucesso da empresa. Tais fatos são os principais responsáveis pelo cumprimento da missão e emprestam à empresa características distintivas. Segundo os entrevistados, todas as empresas dão ampla atenção à sua arquitetura de relacionamento, especialmente de clientes e fornecedores. As pequenas empresas não pesquisam junto a seus clientes e fornecedores em busca de seus fatores chaves de sucesso. O parâmetro utilizado para aquilatar o nível de satisfação de seus clientes é o sinalizador de suas forças e ajuda-as a entender como estão em relação a seus competidores.

Com relação aos processos internos, o balizador do que os empreendedores entendem por fator chave de sucesso é a capacidade da empresa responder com rapidez às demandas de seus clientes. Assim, na percepção dos pequenos empresários, fator chave de sucesso está ligado às estruturas leves e flexibilidade de processos de suas empresas. Esta parece ser uma tese defendida pelos entrevistados "por conceito", isto é, uma empresa pequena deve ser necessariamente leve e ágil como fundamento do seu negócio. 
Análise ambiental. Nessa análise, buscou-se entender como as pequenas empresas de base tecnológica avaliam seu ambiente regional, seu setor econômico de atividade e seu entorno competitivo. Em termos de ambiente regional, nenhum dos executivos das empresas selecionadas mostrou dar atenção a fatores de origem regional que poderiam ajudá-los ou que poderiam dar-lhes vantagens comparativas em relação a seus competidores. Nesse contexto, quando perguntados que fatores regionais poderiam contribuir para o sucesso de suas empresas, apontaram: (a) qualidade da vida na região; (b) nível de educação da mão-deobra; (c) mecanismos locais e regionais para qualificar (educacionalmente) a mão-de-obra; (d) localização próxima de clientes e fornecedores; (e) proximidade com outras empresas de alta tecnologia; (f) benefícios fiscais; (g) transporte público; (h) facilidade de acesso às agências e departamentos governamentais; e (i) sindicatos não beligerantes.

Os entrevistados também deixaram claro que, exceto pela mão-de-obra qualificada e pela chance de acessar novos conhecimentos e tecnologias, as condições do ambiente regional são "de menor importância". Tendo clientes próximos, por outro lado, ajudaria muito seu desempenho, porque eles podem responder melhor às expectativas de seus clientes e administrar mais eficazmente o custo da logística. No caso das pesquisadas, seu principal objetivo é o mercado global. Assim, competências que possam lhes assegurar maior adaptabilidade a seus produtos e respostas mais rápidas ao mercado é sua prioridade principal.

Ambiente de atividades setorial. A análise das atividades setoriais no modelo de Almeida (2003) corresponde à análise das forças competitivas de Porter (1990), acrescido do nível de interferência do governo e dos complementadores. As cinco forças de Porter foram classificadas em intensidade: fraca, média e forte, e, de acordo com sua natureza, em positiva ou negativa. Os entrevistados consideraram o poder de barganha dos clientes como uma força de mediana para forte. O poder dos fornecedores como uma força mediana e novos entrantes, uma força fraco-mediana. Produtos substitutos foram considerados uma força negativa fraco-mediana.

Há três aspectos que chamam a atenção nas respostas dos empreendedores: rivais diretos, governo e complementadores. Na percepção dos empreendedores entrevistados, a ameaça dos competidores diretos foi considerada negativa fraca por causa do caráter especializado dos negócios de suas empresas. A interferência do Governo, por outro lado, foi considerada uma força negativa forte por causa de sua influência sobre o câmbio, políticas de exportação, pesos e benefício de impostos, e de software e hardware. Os complementadores foram considerados também uma força negativa forte, porque empresas de bases tecnológicas dependem, em grande parte, da tecnologia direta ou complementar desenvolvida por outros. Uma empresa não pode pesquisar tudo que precisa e o custo da pesquisa e desenvolvimento torna-se, a cada dia, um peso muito alto a ser pago.

Análise do ambiente da organização. Na análise do ambiente da organização, checouse as análises dos ambientes: Clima, Solo, Operacional e Aspectos Internos, para subsidiar a formulação de estratégias. Os entrevistados indicaram que as informações sobre o ambiente competitivo são coletadas principalmente pelo contato direto com os clientes, em feiras, congressos e na literatura especializada. Fornecedores, Internet, associação profissional e análise periódica de produtos dos concorrentes são igualmente bases cognitivas de informação importantes. Em geral, as informações consideradas importantes são analisadas pelo empreendedor diretamente ou pelo conselho de administração, nas empresas em que há tais conselhos, e somente depois desta análise é que são tomadas as decisões para a formulação das estratégias. Em relação à analise ambiental, somente a análise do ambiente de operação, isto é, a análise do entorno competitivo é considerada significativa e suficiente para a formulação de estratégias pelas empresas estudadas. 
Análise do campo de atuação. Na análise do campo de atuação, de acordo com Almeida (2003), a empresa deveria comparar o que está correntemente fazendo com o que deveria estar fazendo, segundo sua vocação e/ou missão. Essa análise ajuda os empreendedores e executivos a avaliar se a empresa está operando no setor em que deveria estar. Os entrevistados indicaram que existe uma atenção especial no sentido de alinhar as competências da empresa com os nichos de demanda do mercado. Além disso, conforme análise realizada na pesquisa e apresentada no Quadro 01, a experiência com a elaboração do plano de negócio e a compatibilização existente entre o campo de atuação e especialização profissional dos executivos demonstram que todas as empresas operam compativelmente em suas respectivas áreas de especialidade.

Estratégia vigente. O último estágio da fase de Diagnose é identificar a natureza e contribuição das estratégias vigentes. Nas empresas pesquisadas, não se notou preocupação com a identificação das estratégias correntes visando a analisar e decidir manter ou abandonar as estratégias correntes. Uma análise dos investimentos nos balanços financeiros anuais das empresas pesquisadas, no entanto, demonstrou, pela continuidade dos investimentos, a manutenção de estratégias correntes. Em outras palavras, parece haver interesse na manutenção de estratégias de longo prazo, sem quebra de continuidade. Questões que restam a saber, neste caso, são se tais estratégias são intencionalmente mantidas para consolidar competência ou se são compulsoriamente mantidas (por causa da fonte de receita) para garantir sobrevivência da empresa.

\section{A Formulação de estratégias nas empresas pesquisadas}

Como Hamel (2000) já apontou em seu texto Liderando a Revolução, a era das mudanças incrementais está terminada. O domínio competitivo pelos líderes do mercado não possui a mesma estabilidade do passado recente. O autor diz que são necessárias mudanças radicais e duras surpresas para os competidores. No contexto de pequenas empresas de alta tecnologia, apesar da especificidade do negócio, a realidade é basicamente a mesma. O sucesso é muito baseado na inovação e isso significa mudança. Assim, no caso desta pesquisa, também é necessário adotar uma estratégia central (corporativa) que combine os recursos internos, interfaces e posicionamento.

A natureza e nuanças das pequenas empresas de base tecnológica, contudo, requerem um mecanismo mais simples e direto para formular estratégias. O estudo aqui apresentado mostra de várias formas distintas como os executivos dessas empresas pensam e agem, e quais são os grandes obstáculos para a formulação de estratégias em seu contexto, de forma mais complexa ou sofisticada. O que se observou da pesquisa realizada é que o processo de formulação de estratégias em pequenas empresas de base tecnológica é um processo bastante simplificado, mas ao mesmo tempo funcional. O fundamento da estratégia está assentado sobre a natureza do negócio, representado pela habilidade técnica de seu fundador (empreendedor). Assim, a estratégia parece ser um esforço deliberado do empreendedor para fazer funcionar uma idéia dentro do que ele sabe fazer (sua habilidade técnica). Pode-se, então, dividir a formulação da estratégia em pequenas empresas de base tecnológica em três momentos. Num primeiro momento, o empreendedor concebe seu negócio a partir do produto que possui em mãos, condicionado pelas suas próprias habilidades. A observação na pesquisa tem mostrado que a estrutura concebida das empresas pesquisadas não apresenta qualquer desvio inovador sustentado por novas soluções tecnológicas ou de tecnologia da informação. Todas foram concebidas e operam de forma clássica.

Num segundo momento, os empreendedores avaliam seu entorno competitivo, com mais profundidade, para tomarem decisões que consideram estratégicas. Nesse momento, além 
das forças de pressão externas mais diretas sobre a empresa, os empreendedores avaliam os seus recursos e como são os seus processos. A análise é sempre objetiva e altamente pragmática, isto é, voltada para resultados ou para a existência de retornos. O raciocínio é sempre o mesmo: qual o retorno do que estou fazendo? Posso fazer diferente para dar mais retorno? As respostas a essas perguntas levam à eliminação de estratégias correntes ou adoção de novas.

Finalmente, num terceiro momento, os empreendedores formulam suas estratégias competitivas. Para todos os empreendedores entrevistados, o passo mais difícil sempre é tomar uma decisão alternativa, que ele não sabe se vai dar certo ou não. Uma estratégia corrente que esteja funcionando minimamente, em geral não é facilmente derrubada por causa do medo do possível insucesso da estratégia substituta. Adicionalmente, os empreendedores demonstraram superficialidade acerca de domínio tecnológico como fundamento de sua estratégia de negócio. Desses três momentos identificados na formulação de estratégias em pequenas empresas de base tecnológica estudas, formularam-se algumas contribuições ao processo.

\section{Contribuições ao processo de formulação de estratégias}

Como apontado anteriormente, pode-se identificar três fases no processo de formulação de estratégias. Como contribuição, pode-se diagramar estas fases em: (a) Concepção do Negócio; (b) Diagnose; e (c) Formulação da Estratégia. Assim, considerando as particularidades das pequenas empresas de base tecnológica, propõe-se o processo de formulação de estratégias diagramado na Figura 5.

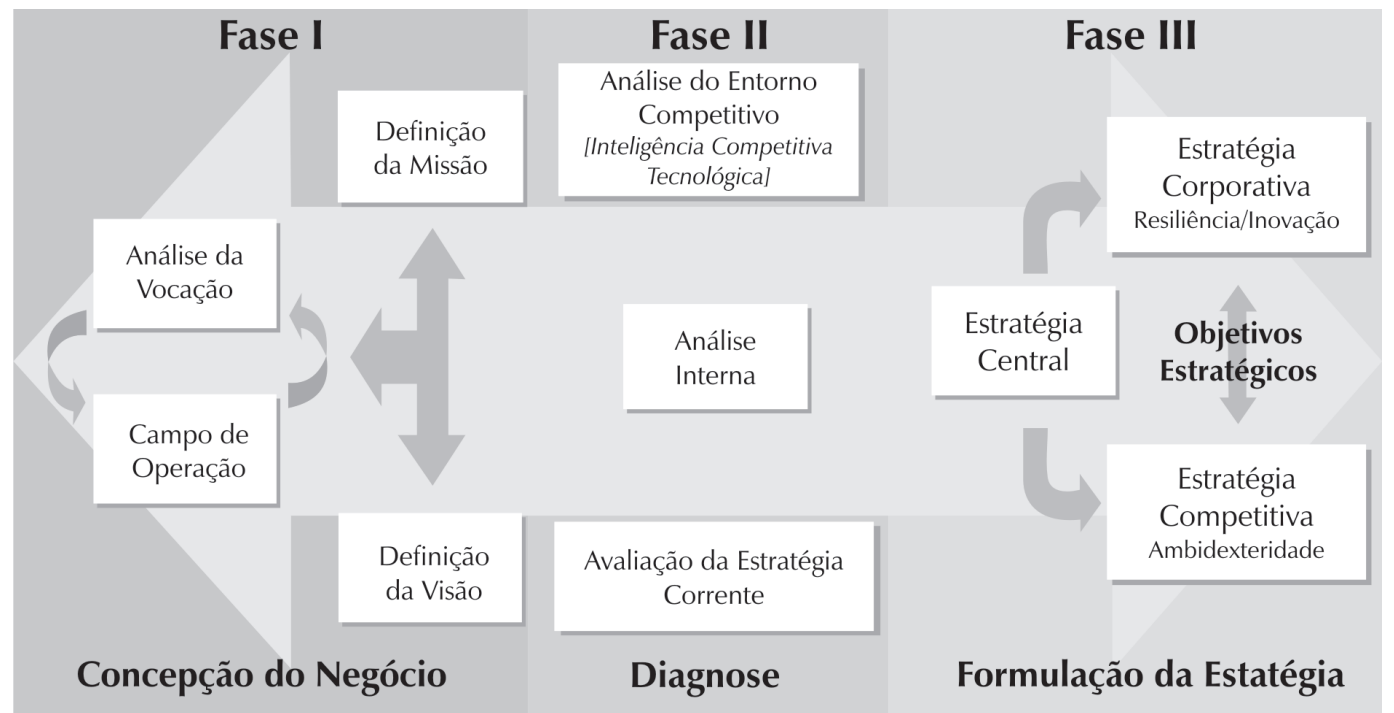

Fonte: Dados da pesquisa.

Figura 5 - Processo de formulação de estratégia em pequenas empresas de base tecnológica.

\subsection{Fase I: Concepção do negócio}

Nessa fase, os empreendedores desenvolvem a idéia central do negócio. Eles precisam decidir onde o negócio deve competir e quão diferentemente ele deve competir. Os competidores estabelecem as premissas básicas do negócio em termos de objetivos, área, recursos disponíveis, arquitetura de relações, fontes de vantagens e coalizões necessárias. 
No contexto da alta tecnologia, os negócios são concebidos com base na análise dos quatro elementos: Vocação, Campo de atuação, Missão e Visão.

Vocação. A concepção do negócio deve começar pela vocação do empreendedor, porque é ela que fundamenta a capacidade central da empresa. Esta é uma habilidade que liga a especialidade profissional do empreendedor à natureza de seu negócio. Ela também influencia diretamente o campo de atuação e o estabelecimento da missão. Apesar de um empreendedor não estar obrigado a ter uma habilidade técnica para gerar um produto, o produto de sua empresa deve estar ligado à especialidade técnica de alguém dentro dela, e a vocação da empresa vai permanecer ligada àquela habilidade técnica.

Missão. A missão deve ser proposta e explicitada com base na natureza e disponibilidade de habilidades técnicas que tornam o negócio único. A missão é parte da concepção do negócio porque define a clientela principal, as necessidades/demandas desta e a forma sob a qual o negócio é levado a efeito. Missão deve ser fonte de inspiração para o posicionamento do negócio, por isso deve ser concisa, curta e bem definida.

Campo de atuação. Definida a vocação e a missão, o empreendedor deve fazer a compatibilização direta entre a especialidade técnica de sua empresa e o ramo de operação de seu negócio. Isso porque uma especialidade técnica determina a natureza e capacidade especial da empresa, mas não necessariamente seu campo de operação. Um desenvolvedor de software, por exemplo, especializado nos requisitos da lei Sarbanes-Oxley (governança corporativa), pode operar em diferentes corporações, mas se sua experiência profissional origina-se em bancos, o campo de atuação de sua empresa de maior desempenho e lucratividade provavelmente será no setor bancário.

Visão. A definição da visão fundamenta o posicionamento competitivo da empresa e do negócio, porque provê o fundamento para uma vista bifocal do negócio (fontes de lucros hoje e no futuro). A visão indica onde a empresa deverá estar no futuro próximo visualizado (5 ou 10 anos). Por isso deve prover direção e motivação para os investimentos, a otimização dos esforços da estratégia corporativa e racionalização no uso dos recursos.

\subsection{Fase II: Diagnose}

Na fase da Diagnose, o empreendedor deve realizar uma análise profunda e completa de seu ambiente de operação. Envolve a Análise do entorno competitivo, a Análise interna e a Avaliação da estratégia corrente.

Análise do entorno competitivo. Esta análise envolve basicamente a caracterização da atratividade do setor e análise do ambiente regional. A análise da atratividade do setor usa o mesmo fundamento das forças competitivas de Porter (1999), porém, com mecanismos de Inteligência Competitiva Tecnológica, isto é, com acesso e monitoramento permanente do seu ambiente tecnológico. A análise do ambiente regional compõe-se da infra-estrutura local e regional, da qualidade de vida e do mercado regional. Infra-estrutura refere-se à disponibilização de espaço físico, de meios de transporte, de benefícios fiscais, da qualidade da força de trabalho e de mecanismos e instituições disponíveis para treinar a mão-de-obra. Qualidade de vida refere-se à infra-estrutura pública disponível à comunidade local. A análise do entorno competitivo, porém, deve fixar-se mais na identificação das mudanças de conteúdo tecnológico do ambiente ou cenário tecnológico no qual está inserida a empresa e no perfil de seus clientes-alvo. Aumentar a capacidade de domínio tecnológico é vital para as pequenas empresas de base tecnológica, porque permite-lhes flexibilidade de processos e agilidade nas respostas.

Análise interna. Essa é uma avaliação cuidadosa das competências internas e capacidades especiais da empresa, compreendendo estruturas, mecanismos, processos e recursos internos.

Rev. Adm. UFSM, Santa Maria, v. I, N. 1, P. 116-133, Jan./ABr. 2008 
A identificação das forças internas ajuda a definir as principais fontes de vantagens competitivas, baseadas nas capacidades especiais, que a empresa pode contar. Tais fontes de vantagens estão ligadas aos Fatores Chaves de Sucesso que devem alavancar o negócio, quando apropriados às oportunidades identificadas nas análises ambientais e de entorno.

Avaliação da estratégia corrente. O último elemento da fase da Diagnose é a avaliação das estratégias correntes da empresa. Antes de alterar, é necessário saber se é preciso redesenhar ou redirecionar as estratégias atuais para compatibilizá-la com os objetivos estratégicos da empresa. Nem todas as estratégias numa empresa são ruins ou não-congruentes com seus objetivos. Portanto, não precisam ser abandonadas. De fato, em muitas pequenas empresas de base tecnológica, as estratégias corporativas são incorporadas por meio de um consistente pensamento estratégico e são, em geral, institucionalizadas sob investimentos corporativos permanentes.

\subsection{Fase III: Formulação de Estratégias}

Na terceira fase do processo de formulação de estratégias em pequenas empresas de base tecnológica, os empreendedores devem desenvolver a Estratégia central. Nesse caso, o ponto crítico é o desenvolvimento da lógica de valor que subsidia a estratégia central.

Estratégia central. A estratégia central é o resultado da combinação das estratégias corporativas e competitivas segundo o conceito de Miles e Snow (1978). Estratégias corporativas sustentam as vantagens competitivas advindas do fazer diferente o que eventualmente já é feito, fazer de forma mais inteligente e fazer de forma planejada (estratégias competitivas), isto é, visando a resultados de maximização de lucro ou de interesses sociais (WHITTINGTON, 2002).

Estratégias corporativas. Para sustentar as vantagens competitivas, as Estratégias Corporativas devem orientar-se para construir a resiliência da empresa na definição de Reinmoeller e Baardwijk (2005). Construir resiliência significa diminuir o grau de sensibilidade da empresa às variações do ambiente, por meio de mecanismos internos (estruturas, mecanismos, domínio tecnológico) que Ihe garantam auto-renovação por meio da inovação. É importante frisar que a estratégia corporativa deve conter, como um dos mecanismos mais importantes da resiliência da empresa, a estratégia de inovação.

Estratégias competitivas. Estratégias competitivas, dentro do conceito explicitado acima, requerem a habilidade de identificar e responder às oportunidades ou antecipar-se às demandas do mercado. A estratégia competitiva, dessa forma, deve construir a ambidextridade contextual, dentro da definição de Birkinshaw e Gibson (2004), garantindo à empresa adaptação constante às mudanças e exigências do mercado, bem como às oportunidades identificadas. O sucesso da estratégia central da pequena empresa de base tecnológica vai ser, então, uma conseqüência do equilíbrio e sustentação das estratégias corporativas e competitivas.

\section{Considerações finais}

A formulação de estratégias para empresas de base tecnológica é normalmente deixada de lado pelos especialistas em estratégia, já que sua atenção volta-se, quase sempre, para as grandes corporações. Por outro lado, as características singulares das pequenas empresas impedem que se transladem diretamente os mesmos mecanismos desenvolvidos para formulação de estratégias em grandes empresas. E os poucos estudos que existem, voltados para as pequenas empresas, focam o conteúdo, não o processo da formulação de estratégias, como no presente estudo. 
Nesta pesquisa, a análise realizada concentrou-se nos processos que poderiam ser mais úteis às empresas em questão. Enfatiza-se, como resultado deste trabalho, três elementos-chave que se julga de grande importância para o processo de formulação de estratégias eficientes no cenário das pequenas empresas de base tecnológica.

O primeiro deles é a Concepção do Negócio. O formato de estruturação e organização de negócios tem mudado radicalmente nos últimos dez anos, e continua mudando. Os negócios tornam-se mais horizontais a cada dia, amparando-se numa rede de organizações parceiras. Empresas de base tecnológica pela sua necessidade de domínio tecnológico, que requerem altos investimentos em pesquisa e desenvolvimento, precisam ser concebidas de forma a garantir as premissas de seus produtos (atualização tecnológica e inovação permanente). Assim, o formato estrutural das empresas de base tecnológica é elemento essencial para o sucesso da empresa, na concepção de seu negócio.

O segundo elemento para o qual se chama a atenção éa Análise do Entorno Competitivo. Como empresas de base tecnológica, em geral, não sofrem grandes problemas de competição direta por causa da singularidade de seus produtos, domínio tecnológico é fundamental para a sua estratégia competitiva. Nesta etapa, chama-se atenção para a Inteligência Competitiva Tecnológica, como um sistema ou mecanismo de apoio à formulação da estratégia corporativa da empresa, pois é ela que vai mostrar como será a estratégia de inovação da empresa, que tipo de alianças estratégicas devem ser construídas e com quem e como devem ser sustentadas e ampliadas suas capacidades especiais.

Finalmente, o terceiro elemento é a formulação de uma estratégia central que contenha a Estratégia Corporativa e a Competitiva. A estratégia corporativa deve orientar-se para construir gradativamente as capacidades especiais da empresa para adaptar-se e inovar. Deve, portanto, conter explicitamente a estratégia de inovação. A estratégia competitiva, por outro lado, deve suportar as vantagens competitivas do negócio. A orientação para as empresas é de desenvolvimento de ambidextridade corporativa, isto é, a capacidade da empresa passar a adaptar-se ao seu ambiente, redesenhando suas estruturas internas de forma a manter agilidade de resposta e flexibilidade em seus processos.

\section{Referências bibliográficas}

\section{ALMEIDA, M. I. R. Manual de planejamento} estratégico. 2: ed. São Paulo: Atlas, 2003.

ACATE. Associação Catarinense de Empresas de Tecnologia. 2005. Glossário. Disponível em: <http://www.acate.com.br/glossario.html>. Acesso em: 12 ago 2007.

ANPROTEC. Associação Nacional de Entidades Promotoras de Empreendimentos de Tecnologias Avançadas. Glossário dinâmico de termos na área de tecnópolis, parques tecnológicos e incubadoras de empresas. Brasília: Anprotec, 2002.

BEAVER, G.; PRINCE, C. Management, strategy and policy in the UK small business sector: a critical review. Journal of Small Business and Enterprise Development, v. 11, n.1, p. 34-49, 2004.

BERRY, M. Strategic planning in small high tech companies. Long Range Planning, v. 31, n. 3, p. 455-466, 1998.

BHIDE, A. The questions every entrepreneur must answer. Havard Business Review, v. 74, n. 6, p. 120-130, 1996.

BIRKINSHAW J.; GIBSON, C. Building ambidexterity into an organization. MIT Sloan Management Review, v. 45, n. 4, p. 47-55, 2004. 
CARVALHO, M. M. et al. Fatores críticos de sucesso de empresas de base tecnológica.

Produto \& Produção, edição especial, v. 4, p. 47-59, 2000.

EISENHARDT, K. M. Building theories from case study research. Academy of Management Review, v.14, n. 4, p.532-550, 1989.

FERRO, J. R.; TORKO-MIAN, A. L. V. A criação de pequenas empresas de alta tecnologia.

Revista de Administração de Empresas, v. 28, n. 2, p. 43-50, 1988.

HAMEL, G. Leading the Revolution. Boston (MA): Harvard Business Review Press, 2000

HILL, C.W.L.; JONES, G. R. Strategic management theory an integrated approach. 6 . ed. Boston: Houghton Mifflin Company, 2004.

KHOGH, G. V.; CUSUMANO, M. A. Three strategies for managing fast growth. MIT Sloan Management Review, v. 42, n. 2, p. 53-61, 2001.

LEITE, E. O fenômeno do empreendedorismo. 3. ed. Recife: Bagaço, 2002.

McCARTHY, B.; LEAVY, B. Phases in the strategy formation process: an exploratory study of Irish SMEs. Journal of the Irish Academy of Management, v. 21, n. 2, p. 55-79, 2000.

MILES, R.E.; SNOW, C.C. Organizational strategy, structure and process. New York: McGraw-Hill, 1978.

MINTZBERG, H.; AHLSTRAND, B.; LAMPEL, J. Safári de estratégia. Porto Alegre: Bookman, 2000 .

MINTZBERG, H.; QUINN, J. B. O processo da estratégia. Porto Alegre: Bookman, 2001.
PINHO, M.S. et al. A fragilidade das empresas de base tecnológica em economias periféricas. Porto Alegre: Ensaios FEE, 2002.

PORTER, M. The competitive advantage of nations. 10. ed. New York: Free, 1990.

Competição: on competition. Rio de Janeiro: Campus, 1999.

REINMOELLER, P.; BAARDWIJK, N. The link between diversity and resilience. MIT Sloan Management Review, v. 46, n.4, p. 61-66, 2005.

RODRIGUES, L. C.; RISCAROLLI, V.; ALMEIDA, M. I. R. Maturação tecnológica e estratégia de inovação In: SIMPÓSIO DE GESTÃO DA INOVAÇÃO TECNOLÓGICA, 23., 2004, Curitiba. Anais ... Curitiba, p. 270-286, 2004.

SANTOS, S. A. A criação de empresas de base tecnológica. São Paulo: Pioneira, 1987.

SEBRAE. Serviço Brasileiro de Apoio as Micro e Pequenas Empresas. Critérios de tamanho da empresa. 2006. Disponível em: <http://www. sebrae.com.br/>. Acesso em: 18 jul. 2007.

SLYWOTZKY, A. J.; MORRISON, D. J. $\boldsymbol{A}$ estratégia focada no lucro: the profit zone. Rio de Janeiro: Campus, 1998.

TREGOE B. B.; ZIMMERMAN, J. W. A estratégia da alta gerência. 2. ed. Rio de Janeiro:

Guanabara, 1988.

WHITTINGTON, R. O que é estratégia. São Paulo: Pioneira, 2002.

YIN, R. K. Estudo de caso: planejamento e métodos. 3. ed. Porto Alegre: Book 